\title{
O RETRATO HOLOGRÁFICO DO GESTOR DA ESCOLA BÁSICA E A NECESSIDADE DE NOVAS POSSIBILIDADES GESTORAS
}

\author{
EL RETRATO HOLOGRÁFICO DEL DIRECTOR DE LA ESCUELA BÁSICA Y \\ LA NECESIDAD DE NUEVAS POSIBILIDADES DE GESTIÓN
}

\author{
THE HOLOGRAPHIC PORTRAIT OF THE CURRENT MANAGER OF THE \\ BASIC SCHOOL AND THE NEED FOR NEW MANAGEMENT POSSIBILITIES
}

\author{
Antonio AMORIM ${ }^{1}$ \\ Alfredo Eurico da MATTA ${ }^{2}$ \\ Kátia Siqueira de FREITAS ${ }^{3}$
}

RESUMO: Este estudo tem como objetivo analisar o perfil holográfico do gestor da escola básica, destacando a urgência na construção e na consolidação de um fazer contemporâneo de gestão, que seja inovador e definidor de novas possibilidades gestoras que garantam a qualidade institucional na gestão da escola. Foram empregados pressupostos da pesquisa qualitativa, fazendo a leitura crítica de documentos e da literatura que trata da gestão e da inovação dos processos gestores na escola. Os resultados da análise indicam que: há um perfil conservador dos gestores que atuam na escola básica; existe a necessidade de garantir a inovação educacional e a criação de um espaço institucional transformador, que possibilite a formação de um perfil democrático para o novo gestor escolar e que alcance seus liderados, com a efetivação de uma práxis institucional que promova a qualidade da gestão e da vida educacional nas escolas.

PALAVRAS-CHAVE: Gestão escolar. Inovação educacional. Perfil holográfico.

RESUMEN: Este estudio presenta como objetivo hacer un análisis del perfil holográfico del gestor de la escuela básica, poniendo de relieve la urgencia en la construcción de una práctica contemporánea de gestión, innovadora, que establezca nuevas posibilidades gestoras y garanticen la calidad institucional, la gestión de la escuela. Se emplearon presupuestos de la investigación cualitativa, la lectura crítica de documentos y la literatura que se ocupa de la gestión e innovación de procesos gestores en la escuela. Los resultados del análisis muestran que: existe un perfil conservador de los directivos de la escuela básica; hay que asegurar la innovación educativa y la creación de un espacio institucional transformador, que permita la formación de un perfil democrático al nuevo gerente escolar y lleguen a sus subordinados, con el

\footnotetext{
${ }^{1}$ Universidade do Estado da Bahia (UNEB), BA - Brasil. Professor Titular. E-mail: antonioamorim52@gmail.com

${ }^{2}$ Universidade do Estado da Bahia (UNEB), BA - Brasil. Pesquisador do CNPQ. Professor do DMMDC e PPGEDUC da UNEB. Email: alfredo@matta.pro.br

${ }^{3}$ Professora e pesquisadora da UCSAL.E-mail: sfkatia@gmail.com
} 
establecimiento de una práctica institucional que promueva la calidad de la gestión y de la vida educativa en las escuelas.

PALAVRAS CLAVE: Gestión de la escuela. Innovación educativa. Perfil holográfico.

ABSTRACT: This study aims to analyze the Profile Manager basic school holographic, highlighting the urgency in construction and consolidation of a contemporary management process, which is innovative and presents new management possibilities to ensure institutional quality, the management of the school. We obtained results that: there's a conservative profile of the managers working in elementary school; There is a need to ensure the educational innovation and the creation of an institutional space transformer, enabling the formation of a democratic profile for the new school manager, with the establishment of an institutional practice that promotes the quality of management and educational life in schools.

KEYWORDS: School management. Educational innovation. Holographic profile.

\section{Introdução}

Ousamos trazer no título deste artigo uma alusão à holografia, referindo-nos ao perfil holográfico do gestor da escola básica. Portanto, tomamos emprestado da física, com a pesquisa de David Bohm, e da neurofisiologia, a partir das investigações de Karl Pribram com relação à noção de que a holografia, “[...] reprodução tridimensional de imagens por laser" ${ }^{\prime 4}$, pode dar uma ideia da complexidade e dos enigmas do mundo dos gestores em educação, especialmente os da escola básica. Nesse sentido, questionamos que desafios enfrentam e que conhecimentos e competências são requeridos para o estabelecimento da educação básica e da qualidade compatível com o pensamento presente, o mundo projetado e a percepção holográfica da sociedade, mediante a qual o globo terrestre seria um holograma.

Vejamos então o contexto holográfico da educação básica no Brasil nos anos de 2013 e 2014. O Brasil tinha mais de 202 milhões de habitantes em 2014. O Censo Escolar de 2014 registrou a existência de 188.673 mil escolas de educação básica no país, entre públicas e privadas. Dados desse mesmo senso indicam que essas instituições recebiam diariamente um total de 50 milhões de alunos. Todavia, continuavam apresentando também um percentual de fracasso escolar, ou seja, evasão e repetência,

4 Disponível em: <https://contraeducacao.files.wordpress.com/2012/09/livro-o-universo-holograficomichael-talbot.pdf>. Acesso em 26 jun. 2016. 
considerados como desperdício de recursos financeiros e de energia humana, que atinge um total de 7,3\% nos anos iniciais e 15,2\% nos anos finais do ensino fundamental. Já no ensino médio, o percentual geral de fracasso escolar identificado foi de 19,8\%. Enquanto isso, o processo de universalização do ensino fundamental atingiu a taxa de em 97\% dos alunos, em idade escolar, nos 5.561 municípios brasileiros.

Estamos, então, com um conjunto de escolas e uma população estudantil que merecem melhor destino educacional, com nova perspectiva formativa, para fazer frente às necessidades inerentes ao seu desenvolvimento integral como pessoa humana e às demandas apresentadas pela sociedade, cujo modelo de desenvolvimento confere valores relevantes à educação escolarizada, ao capital, ao trabalho, ao sucesso profissional e pessoal. Todos os que são percebidos como bem-sucedidos tornam-se referências de superação em vários campos. Estamos nos referindo às diversas dimensões da vida em sociedade, numa alusão à possível dimensão holográfica da vida e da formação escolarizada. Contudo, em geral, a preparação desses gestores vem sendo conduzida de modo considerado objetivo, com foco em determinados aspectos e muito pouco holográfico. Já para David Bohm e seus seguidores, o mundo objetivo não é real, a realidade é muito mais profunda do que podemos ver e observar ${ }^{5}$.

Por isso, entendemos que também é oportuno que a gestão escolar esteja intimamente interligada com o dinamismo das inovações na educação, nas demais áreas do conhecimento, na sociedade, no sistema escolar e na própria unidade escolar. Esses aspectos são entendidos, atualmente, como sendo uma necessidade histórica, para fazer frente às demandas por acesso, permanência e sucesso educativo, envolvendo, portanto, a emancipação e a construção da cidadania para todos os milhões de estudantes que frequentam a educação básica em todo o país. É preciso reconhecer a realidade desse nível de ensino para diagnosticar e compreender a situação vivenciada pelos dirigentes escolares, projetando caminhos inovadores e possíveis soluções para muitos dos problemas vividos pela equipe de alunos, professores, gestores, funcionários e familiares.

Observamos que os gestores, quando adentram o realista ambiente educacional da escola, desde o início se deparam com inúmeras desilusões que impactam no fluir das suas atividades profissionais e das dos demais membros da instituição. São exemplos: professores com dificuldades formativas; alunos bi e tri repetentes e, em boa

\footnotetext{
${ }^{5}$ Disponível em: <http://somostodosum.ig.com.br/conteudo/c.asp?id=10940>. Acesso em 21 jun. 2016.
} 
parte, com problemas de saúde física e mental, como fome, bipolaridade, hiperatividade, deficiências auditivas e visuais, assim por diante; espaço físico inadequado para a prática educativa, cultural e desportiva; equipe de funcionários e de professores com salários aviltantes e, por vezes, com formação inadequada para entender e atender às reais necessidades do conjunto de elementos e pessoas envolvidas com o fazer educativo; falta de valorização social do trabalho educacional; desencontro na consolidação de um projeto democrático de educação e de escola; dificuldades burocráticas, relacionais, financeiras e materiais para fazer uma boa gestão institucional e para manter a escola receptiva ao novo e às demais instituições da sociedade. Enfim, há um conjunto de condições, por vezes adversas ao bom desenvolvimento dos trabalhos pedagógicos e gestores, que cotidianamente desafiam a capacidade dos que lidam com os problemas a buscarem novas soluções, que impactem positivamente na melhoria da qualidade da educação básica e na emancipação dos cidadãos.

Diante desse panorama com uma realidade plena de problemas e desafios multifacetados, consideramos a importância de estudos dessa natureza, pois compreendemos que essas problemáticas podem estar contribuindo para o desencontro do projeto atual de escola brasileira, bem como para o aprofundando da falta de qualidade do ensino (FREITAS; PILLA, 2006) e da consequente persistência da evasão e repetência, o que equivale a fracasso escolar, como é o caso em disciplinas como português e matemática. Temos, na prática cotidiana, um modus operandi de escola pública que não tem diagnosticado com profundidade, nem vencido as questões sociais, culturais, pedagógicas, psicológicas, que permeiam o seu ambiente interno e externo. Consequentemente, entendemos que há uma superficialidade na prática da política de inclusão social, na luta pela igualdade de gêneros e de raça, na sistemática de valorização da profissão docente, na formação e na escolha dos gestores, sempre à procura por um modelo educacional democrático e participativo, que consolide os valores humanos tão necessários à vida cidadã nos dias atuais (AMORIM, 2012).

Por isso, o estudo está organizado por esta introdução, onde destacamos as considerações preliminares da temática; em seguida, referimo-nos à questão metodológica adotada, enfatizando a pesquisa qualitativa como sendo adequada à investigação empreendida; posteriormente, estabelecemos o retrato holográfico do gestor escolar; focamos as possibilidades gestoras que podem inovar o ambiente escolar; enfim, tecemos as considerações finais deste estudo com as referências adotadas. 


\section{Percurso metodológico}

A realização deste estudo foi possível graças à utilização da pesquisa qualitativa como pano de fundo, uma vez que concordamos com a assertiva de Creswell (2010, p. 43) sobre esse tipo de trabalho quando afirma que é: “[...] um meio para explorar e para entender o significado que os indivíduos ou os grupos atribuem a um problema social ou humano". Compreendemos que a investigação qualitativa é uma sistemática que considera o movimento de coleta de dados e de informações aberto, com a valorização do processo interpretativo, sempre tendo como perspectiva a complexidade do problema em estudo, as nuances humanas que são geradas nos procedimentos, com a revelação das especificidades e da totalidade do objeto que está sendo investigado.

Da mesma forma, como instrumentalização técnica, privilegiamos trabalhar com a investigação documental e bibliográfica, fazendo uso dos dados do Censo Escolar de 2013 e de 2014, e do trabalho de investigação efetivado pelo grupo de pesquisa: Gestão, Organização, Inovação e Políticas Públicas em Educação, com registro no Conselho Nacional de Desenvolvimento Científico e Tecnológico - CNPQ, com a utilização de referências bibliográficas de autores que são estudiosos do assunto, como Dourado (2007), Luck et al (2012), Amorim (2007, 2012 e 2015) e Paro (2007), entre outros. Tudo isso para situar e analisar o panorama histórico e atual em que vivemos e que permeia os diferentes saberes e fazeres da escola, destacando os seus procedimentos gestores e formativos.

\section{Retrato holográfico da situação institucional dos gestores na escola básica atual}

As informações e os dados do Censo Escolar de 2013 foram divulgados pelo Instituto Nacional de Estudos e Pesquisas Educacionais - INEP, apresentando o trabalho realizado junto a mais de 54 mil escolas em todo o país, explicitando o desencontro existente no atual contexto da gestão da escola básica. Em primeiro lugar, os dados revelaram que $95 \%$ dos dirigentes que responderam ao questionário do Censo Escolar de 2013 destacaram a existência de condições satisfatórias para o exercício do cargo, em cada escola onde responde pela gestão, tendo o apoio da comunidade para a realização do seu trabalho. Apenas $5 \%$ dos dirigentes consideraram que não existem condições de trabalho e não têm o apoio da comunidade para o exercício do cargo ou função. 
Esse é um posicionamento preocupante e parece estar dissociado da realidade, se considerar o tamanho da problemática vivida em termos de infraestrutura, como pode ser inferido na análise complementar das informações do Censo Escolar de 2014. Essas informações ajudaram a compor o seguinte quadro: apenas $36 \%$ das escolas públicas têm biblioteca, $16 \%$ ainda têm sanitários funcionando fora do prédio escolar, apenas $47 \%$ contam com rede de esgoto, apenas $70 \%$ das escolas contam com água que vem via rede pública, 54\% dos dirigentes dizem que há insuficiência de recursos financeiros, somente $45 \%$ têm laboratório de informática, $45 \%$ não apresentam sala para os professores, não há um movimento de formação crítica e reflexiva voltado para os alunos e $33 \%$ dos gestores não têm espaço próprio para desenvolver as suas atividades profissionais.

Essas dificuldades materiais, aliadas às condições humanas e pedagógicas, formam o retrato holográfico, ou seja, o retrato total, que considera o tamanho e enredamento do cipoal, com todas as dimensões possíveis da problemática referida, demonstrando o grau de complexidade e carência da situação de nossas escolas, em pleno início de século XXI (AMORIM, 2007). De uma maneira geral, ousamos afirmar que a escola sofre o descaso decorrente das ações não implementadas pelos políticos que se furtam de tomar decisões efetivas em prol da elevação dos níveis socioeconômico e intelectual da população brasileira que frequenta a escola pública. Com isso, eles se mantêm guardiões da classe dominante hegemônica, pois é sabido que mais educação de qualidade para a população menos favorecida financeiramente gera mais demandas e reivindicações por mais direitos, inclusive por mais e melhor qualidade de todos os serviços públicos. A precariedade desses serviços é evidente. Resulta da malversação das verbas públicas, da corrupção e manutenção do modelo capitalista em que vive a sociedade contemporânea, com a falta de qualidade dos serviços educacionais, quer propedêutica quer técnica, para enfrentar a sociedade do desemprego generalizado, da desagregação familiar, dos altos índices de violência, da falta de espaço físico adequado para viver, da desinformação cultural e social (BRANDÃO, 2005).

Falar da complexidade da vida escolar é ter que despertar a gestão para conhecer e intervir nas questões não somente estruturais, mas também na dinâmica pedagógica e administrativa da instituição escolar e do sistema de ensino, assim como nas problemáticas afetivas e relacionais. É buscar alternativas para responder sempre às indagações fundamentais que são colocadas no dia a dia, a exemplo das questões: qual 
de fato é a escola pública que nós temos hoje na sociedade brasileira e qual é a escola que precisamos e queremos construir para vencer os obstáculos que impedem o desenvolvimento de cidadãos éticos e competentes para o enfrentamento dos problemas da contemporaneidade? Quais são os pontos de mudança visíveis em nosso dia a dia e referentes à sala de aula, à participação da comunidade, à estruturação da organizacional física e à liderança da escola? Quais normas determinam os papéis que serão exercidos pelos atores sociais dentro e fora da escola? Como deve ser construído o Projeto Político Pedagógico da instituição e qual deve ser a sua dinâmica de consolidação e suas interfaces de poder? Não nos propomos a responder essas indagações neste artigo, mas citá-las, sinalizando o emaranhado de questões a espera de soluções por parte da população.

No meio de tanta complexidade institucional, social e política, há a responsabilização imputada aos gestores e questionamentos que extrapolam seu poder de decisão e cujas respostas só ocorrem em cadeia crescente ou decrescente de poder. Um dos pontos menos cuidados é o desenvolvimento do conhecimento das políticas e das competências de um gestor escolar, que por isso mesmo atua, muitas vezes, como se fosse ou o culpado da falta de qualidade ou o salvador da pátria, aquele que sabe e resolve tudo, o "Dr. Resolve Tudo", apresentando, com frequência, solução sofrida e improvisada. O quadro a seguir traça o perfil atual desse gestor escolar, demonstrando que $64 \%$ deles têm mais de oito anos de formação, que, aproximadamente, $70 \%$ atuam com carga horaria total de quarenta horas semanais de trabalho, para desenvolver as suas atividades gestoras nas escolas brasileiras e resolver todos os problemas considerados de sua responsabilidade, podendo, se têm competência adequada, desempenhar com qualidade suas funções durante o seu tempo contratual de trabalho.

É preciso destacar ainda que os cursos de pedagogia (41\%) e as demais licenciaturas (36\%) juntas são responsáveis por $77 \%$ do processo formativo dos gestores da escola básica no Brasil, conforme apresentado no Quadro 1 a seguir. É interessante observar também que a maior parte deles (64\%) indica ter mais de oito anos de tempo de formação. Com a velocidade das mudanças científicas, técnicas e tecnológicas que ocorrem na sociedade, é possível questionar se eles se atualizaram e se renovaram para enfrentar as inovações e criar novas oportunidades de desenvolvimento individual e coletivo. É viável interrogar qual o papel desses profissionais municipais e estaduais na atualização e na renovação das condições básicas de trabalho. 
Quadro 1: Retrato holográfico do gestor da escola básica.

\begin{tabular}{|c|c|}
\hline CATEGORIAS & INDICADORES \\
\hline Formação & $\begin{array}{l}\text { - } 41 \% \text { dos dirigentes têm formação em pedagogia; } \\
\text { - } 36 \% \text { em outras licenciaturas; } \\
\text { - } 4 \% \text { têm formação em Normal Superior; } 6 \% \text { formação de nível Médio; } \\
\text { - } \quad 13 \% \text { apresentam formação superior em outros cursos que não são Licenciatura. }\end{array}$ \\
\hline $\begin{array}{l}\text { Tempo de } \\
\text { formação }\end{array}$ & $\begin{array}{l}\text { - } 36 \% \text { dos dirigentes têm mais de } 15 \text { anos de formação; } \\
\text { - } 28 \% \text { estão com } 8 \text { a } 14 \text { anos de formação; } \\
\text { - } 28 \% \text { têm de } 3 \text { a } 7 \text { anos; } \\
\text { - } \quad \text { Apenas, } 8 \% \text { dos dirigentes têm dois anos ou menos de formação. }\end{array}$ \\
\hline $\begin{array}{l}\text { Origem da } \\
\text { instituição que } \\
\text { realizou o curso } \\
\text { superior }\end{array}$ & $\begin{array}{l}\text { - } 59 \% \text { fizeram curso em instituições privadas de ensino superior; } \\
\text { - } 39 \% \text { em instituições públicas, sendo a maioria de ensino superior pertencente à } \\
\text { rede estadual; } \\
\text { - } 64 \% \text { são universidades, } 20 \% \text { faculdades isoladas e } 11 \% \text { são centros } \\
\text { universitários. }\end{array}$ \\
\hline $\begin{array}{l}\text { Modalidade de } \\
\text { ensino cursada }\end{array}$ & $\begin{array}{l}\text { - } 81 \% \text { dos dirigentes responderam que realizaram o curso superior na modalidade } \\
\text { presencial; } \\
\text { - } 11 \% \text { semipresencial e } 8 \% \text { em cursos à distância. }\end{array}$ \\
\hline $\begin{array}{l}\text { Tempo de atuação } \\
\text { do dirigente em } \\
\text { educação }\end{array}$ & $\begin{array}{l}\text { - } 51 \% \text { dos dirigentes trabalham em educação há mais de } 20 \text { anos; } \\
\text { - } 38 \% \text { têm entre } 10 \text { a } 19 \text { anos de exercício na educação; } \\
\text { - } 11 \% \text { dos dirigentes trabalham em educação até } 10 \text { anos. }\end{array}$ \\
\hline $\begin{array}{l}\text { Carga horária de } \\
\text { trabalho na escola } \\
\text { como dirigente }\end{array}$ & $\begin{array}{l}\text { - } 67 \% \text { responderam que tem até quarenta horas semanais de exercício na escola; } \\
\text { - } \quad 26 \% \text { têm mais de quarenta horas; } \\
\text { - } 3 \% \text { têm até vinte horas de trabalho e } 4 \% \text { até trinta horas de atividades semanais. }\end{array}$ \\
\hline $\begin{array}{l}\text { Participação na } \\
\text { construção do } \\
\text { projeto político } \\
\text { pedagógico da } \\
\text { escola }\end{array}$ & $\begin{array}{l}\text { - } 42 \% \text { consideram que o foi construído pelos professores, pais, servidores, } \\
\text { estudantes e os gestores da escola; } \\
\text { - } 19 \% \text { dos gestores dizem que o Projeto foi consolidado por um grupo de } \\
\text { professores, tendo a participação dos gestores da escola; } \\
\text { - } 15 \% \text { dos gestores afirmam que o modelo de projeto da escola é o mesmo } \\
\text { encaminhado pela Secretaria de Educação; } \\
\text { - } 4 \% \text { das escolas, os gestores declararam que não existe Projeto Político } \\
\text { Pedagógico em vigor. }\end{array}$ \\
\hline $\begin{array}{l}\text { Processo de } \\
\text { escolha dos } \\
\text { gestores escolares }\end{array}$ & $\begin{array}{l}\text { - } 10 \% \text { dos dirigentes são escolhidos através de seleção institucional; } \\
\text { - } 21 \% \text { através do processo de eleição; } \\
\text { - } 14 \% \text { através do processo conjugado de seleção e de eleição; } \\
\text { - } 12 \% \text { são escolhidos através de indicação técnica; } \\
\text { - } 22 \% \text { são ainda através de indicação de políticos; } \\
\text { - } 21 \% \text { através de outras indicações. }\end{array}$ \\
\hline $\begin{array}{l}\text { Remuneração dos } \\
\text { gestores }\end{array}$ & $\begin{array}{l}\text { - } 24 \% \text { recebem acima de sete salários mínimos; } \\
\text { - } 26 \% \text { dos gestores ganham de cinco até sete salários mínimos; } \\
\text { - } 24 \% \text { recebem de três e meio a cinco salários mínimos; } \\
\text { - } 18 \% \text { ganham de dois a três salários mínimos e meio; } \\
\text { - } 5 \% \text { recebem de um a dois salários mínimos; } \\
\text { - } 3 \% \text { ganham menos de um salário mínimo como dirigente escolar. }\end{array}$ \\
\hline
\end{tabular}

Fonte: Elaboração própria a partir dos dados do MEC/INEP/DEED de 2013, 2014 e 2015.

Ou seja, a situação educacional, material e humana desses profissionais é diversificada e complexa, exigindo um olhar reflexivo para a condição humana de trabalho e para o enfrentamento com as novas realidades sociais. Da mesma forma, é preocupante o processo de desvalorização financeira desses profissionais (assim como dos professores, funcionários e demais pessoal do campo da educação), que pode ser, de 
fato, compreendida, quando juntamos o salário bruto que eles recebem com os adicionais percebidos por todos. Os dados revelam que 50\% dos dirigentes escolares no Brasil recebem de três e meio a sete salários mínimos, por mês, para exercer esse cargo profissional. A análise dos resultados obtidos demonstra que, se considerarmos o salário mínimo do final do ano de 2015, 50\% dos diretores escolares recebiam um salário que variava de $\mathrm{R} \$ 2.534,00$ a $\mathrm{R} \$ 5.068,00$, o que demonstra ser muito pouco para o exercício de uma profissão tão importante em nosso sistema de ensino, por 40 horas de trabalho semanais.

A análise dos resultados obtidos indica ainda que a disparidade remunerativa chegava a tal ponto que, segundo o Censo Escolar de 2013, um total de 3\% dos cinquenta e quatro mil entrevistados recebia menos de um salário mínimo para exercer as atividades escolares. Isto corresponde a cerca de mil seiscentos e vinte dirigentes que estão atuando com condição financeira aviltante para trabalhar no sistema público de ensino.

Da mesma forma, o mesmo Censo identificou também que 45\% desses profissionais são escolhidos por processos de seleção, de eleição ou de eleição/seleção ao mesmo tempo. Enquanto isso, 22\% deles ainda são escolhidos pelo processo de indicação política. Considerando o total de 54 mil diretores participantes da investigação, $22 \%$ correspondem a onze mil oitocentos e oitenta que ainda são agraciados, politicamente, para exercer uma função sobre a qual, muitas vezes, não têm o menor preparo pessoal, cultural, acadêmico, prático ou institucional para exercer, numa clara demonstração da falta de critérios éticos e de valorização da qualidade educacional nas políticas de indicação, seleção e escolha dos mesmos.

Merece destaque, ainda, a modalidade de ensino presencial, que é responsável por $81 \%$ da formação dos dirigentes das escolas. Isto coloca a importância do ensino presencial atuando na formação dos dirigentes escolares, na maioria das escolas espalhadas pelo território nacional. Outro dado significativo revelado pelo Censo Escolar de 2013 sinaliza que essa função é exercida, há mais de 10 anos, por $21 \%$ dos informantes; $25 \%$ desenvolvem essa atividade entre 5 e 10 anos e $30 \%$ tem menos de 10 anos de profissão conduzindo as responsabilidades escolares. Ou seja, notamos que $67 \%$ da amostra pesquisada têm entre dois e dez anos de atuação na função. Além disso, 19\% deles exercem a direção na mesma escola há menos de um ano; 14\% têm de um a dois anos de atuação; $34 \%$ estão na posição entre dois e cinco anos; $22 \%$ têm de cinco a dez anos e $11 \%$ têm acima de dez anos de atuação como dirigente na mesma escola. 
De acordo com Amorim (2012), a formação, a atuação e a melhoria de desempenho estão muito relacionadas à visão de mundo que o profissional tem sobre si mesmo, sobre o papel que os demais membros da escola devem desempenhar e o significado do papel que a sociedade pode exercer em relação à importância e prioridade da educação e da escola. Compreendemos que o gestor precisa atuar de maneira reflexiva como líder integrador, para proporcionar um conjunto educacional e cultural que promova a integração e participação das pessoas que compõem as comunidades interna e externa à instituição e dos sistemas de ensino, para melhor suporte à melhoria das condições educacionais.

A busca pela sintonia entre a realidade e os sonhos no seio das escolas passa pela reflexão de pessoas sobre uma instituição que é constituída com toda complexidade orgânica. Isso poderá representar o exercício dinâmico do pensar o espaço escolar e seu entorno para acolher a complexidade humana que se faz presente dentro e fora da escola e refletir, de maneira ampliada, sobre o fortalecimento dos valores éticos, estéticos e políticos que devem predominar no contexto da gestão escolar e nortear o cidadão em formação.

Conforme, Luck et al (2012, p. 44), a pouca motivação de parte dos gestores, funcionários e professores pode ser decorrente de:

[...] insatisfação com condições desfavoráveis ou ruins de trabalho; de problemas de orden pessoal; de uma situação específica associada ao trabalho tal como um grupo de estudantes particularmente difícil de lidar; do estresse resultante de muitos anos de trabalho em situações de muita exigencia; do cansaço devido da falta de variedade de desafíos, da insatisfação com o salário e beneficois ou, ainda da desmoralização sentida pelo fato da escola estar vivendo dificuldades financeiras.

Não podemos esquecer, também, que o mundo atual vem sendo pensado, ainda, como global e único. E isto, segundo Bauman (2008), representa a visão de uma sociedade homogênea, toda igual e repleta de certezas. Nesse sentido, a escola e a comunidade social na qual vivem fazem parte de um panorama ambíguo: de (in)certezas, de realização de uma função educativa única, não acolhem as diferenças existentes, as incertezas que constituem elementos substanciais no ambiente contraditório que é a escola; embora parecendo tratar-se de um lugar onde tudo é definitivo para todos, essa imagem não corresponde à realidade. 
Assim, entendemos que as chamadas "certezas pedagógicas" podem estar ocupando o tempo e o espaço da escola de maneira alienada, criando uma atmosfera de que tudo está resolvido, ou que pode ser resolvido sem explicações, distanciando o conjunto da comunidade escolar da possibilidade de recriar os seu espaços dinâmicos de (re)construção de diferentes saberes, de colaborar para a efetivação de uma gestão democrática. É interessante notar, no Quadro 1, que menos da metade (42\%) dos participantes consideram que o Projeto Político Pedagógico (PPP) foi elaborado pelos professores, pais, servidores, estudantes e os gestores da escola. É possível inferir que a elaboração do PPP, em $58 \%$ dos casos, não conta com a colaboração do conjunto dos beneficiados com o trabalho pedagógico. Os mesmos também não se envolvem com o planejamento e tomada de decisões, deixando para os outros (provavelmente os professores) as decisões relativas aos aspectos pedagógicos. Decorre daí a concentração do poder decisório nas mãos dos poucos que acreditam ter o direito e dever de realizar tal tarefa.

O resultado das certezas ideológicas e teóricas que são construídas no tempo e no espaço atual da escola, mesmo da escola básica, tem contribuído para a homogeneização dos saberes, das decisões educacionais que fazem emergir muitas certezas, requerendo uma tomada de posição do gestor, que precisa se definir diante do pensar e do refazer o conhecimento que brota da vida complexa, dentro e fora das instituições de ensino.

\section{Construção de novas possibilidades gestoras}

A construção de uma nova possibilidade gestora exige mudanças profundas nas políticas educacionais, na formação dos gestores escolares, municipais e estaduais, assim como dos conselhos e colegiados escolares, até mesmo na forma de ver e de fazer a educação nas instituições públicas de ensino, sendo relevante considerar o ideário traçado por Veiga (2001, p.51), quando exige a necessidade de:

- romper de maneira definitiva com as estruturas mentais e organizacionais fragmentadas existentes na educação e nos sistemas de ensino;

- definir e consolidar o vir a ser da escola baseado em princípios e diretrizes contextualizadas; 
- criar utopias pedagógicas a partir da vontade política da comunidade escolar, rompendo com o individualismo e estabelecendo a parceria e o diálogo franco;

- fortalecer o processo de diagnóstico da escola, considerando a avaliação como sendo necessária para solucionar os problemas enfrentados individual e coletivamente.

Não podemos desconsiderar que, historicamente, o modelo atual de escola tem mais de mil anos de reprodução (AMORIM, 2012). Já destacamos que se trata de um modelo escolar que continua a reproduzir e a transmitir um tipo de conhecimento, utilizando velhos métodos, antigas formas de organização do espaço escolar, que reforçam a pedagogia dos conteúdos, pela transmissão de conhecimentos que colocam a escola no caminho do imobilismo, a estar em descompasso em relação à inovação educacional que é exigida pela contemporaneidade.

Além de tudo isso, observamos que a arquitetura é a mesma. O tempo passa, a vida passa, novas metodologias e novas práticas educativas são exigidas. Mas ainda percebemos que a escola permanece imutável em sua essência, repete sempre aquelas sistemáticas que já vêm sendo pré-formatadas ao longo dos anos, não há lugar para o novo, para os processos de transformação que vêm sendo exigidos pela sociedade, pelo desenvolvimento produtivo e pelas novas tecnologias.

Nesse sentido, acrescentamos a relevância da escola ter mais que um processo de informatização consolidado, exigência já caduca, já que deveria ter sido plenamente realizada no final do século passado e aconteceu só parcialmente. Essa falta de sintonia pode ser percebida mediante a atual situação do avanço das tecnologias da informação e da educação. Já se trata, agora, de incorporar a sua cultura e práxis mais corriqueira nos sistemas e procedimentos organizacionais digitais, como suporte à educação a distância, ao registro e produção de conhecimento local, e de todo um conjunto de práticas que deveria guiar a escola, para levá-la a uma condição de instituição mediadora, entre o local, o conhecimento ali construído e o contexto mais amplo vivido pela sociedade, ambos relacionados e atuando em rede mundial. Esse seria um avanço dinâmico. Um desafio às escolas brasileiras e aos seus gestores de hoje é: conduzir este processo de atualização organizacional, de produção de conhecimentos e de construção de uma nova realidade educacional compatível com a época em que vivemos e com o futuro. 
A construção de um clima democrático, inovador, que promova a transformação do que temos hoje passa pelo entendimento de que as instituições de ensino básico precisam estar em sintonia com o seu tempo, permitindo a renovação do potencial imaginário e das utopias dos seus membros, para possibilitar a mudança estrutural dos processos vivenciados nos ambientes educacional e social. Há que se pensar e promover uma integração entre o tempo contemporâneo com as propostas pedagógicas, com os diferentes saberes e fazeres vivenciados pela comunidade escolar (AMORIM, 2007).

Para tanto, é preciso que os alunos, os professores, os gestores e os pais de alunos percebam a qualidade pedagógica que pode existir na construção do saber cotidiano, para inovar essas práticas educacionais, para garantir uma educação de qualidade no âmbito institucional. Não esquecendo que, para Jovchelovitch (2001, p.24), os saberes sociais têm uma dinâmica e um alcance social relevante, pois, segundo ela: "Nas nossas sociedades dinâmicas, eles se movem, eles se deslocam como a gente vai e vem. E quando eles se deslocam, eles deixam contextos com relações específicas e chegam a outros contextos com outras relações específicas e nesse processo eles se transformam".

Em qualquer situação de inovação da gestão e do modelo educacional, há sempre um rol de características evolutivas, que pode ser acompanhado no desenvolvimento das alterações que serão produzidas: a inovação educacional não acontece de forma isolada (FERNANDES, 2002). Ela é sempre um percurso que envolve pessoas ou grupos de pessoas, ou instituições, e que visa sempre à concretização de mudanças na cultura ou subcultura de uma instituição. E por ser um percurso, a inovação da gestão e da educação implica em etapas progressivas de transformações do ambiente educacional ou escolar, atuando para refazer caminhos metodológicos, projetos político pedagógicos e curriculares, práticas docentes e gestoras, comportamentos individuais e coletivos (AMORIM, 2015).

Todavia, as políticas educacionais e os sistemas de ensino não conseguem responder às rápidas mudanças requeridas pela sociedade para manterem-se na liderança e vanguarda dos conhecimentos científicos e tecnológicos, por várias razões que não cabe explicitá-las, pois são do domínio publico, sendo que uma é necessário pontuar: a malversação dos recursos públicos em geral e em especial dos destinados à educação. Contudo, a educação básica de qualidade é essencial, e para tanto a "[...] preparação e permanente atualização dos profissionais da educação constituem o centro das preocupações [...]" (FREITAS; ROCHA, 2016, p.266). 
Diante de tudo isso, é necessário questionar: será possível pensar utopicamente ou efetivamente a perspectiva de uma escola verdadeiramente transformadora? Uma escola que tenha um gestor com um perfil dinâmico, democrático, criativo, receptivo ao novo e a mudanças pertinentes? Para responder a essas questões é preciso não esquecer que ainda vivemos na escola sob o guarda-chuva do velho tecnicismo, mas que é possível renovar esse panorama. Muñoz (2007) chama a nossa atenção para o fato de que este tecnicismo não tem permitido o surgimento do processo de inovação nas atividades educacionais, aquelas que são realizadas dentro da escola, pois elas têm priorizado os resultados em detrimento dos processos. Esse tecnicismo exagerado desumaniza o processo educativo quando oferece uma ênfase exagerada ao uso das técnicas, por vezes, inapropriadas, em detrimento de metodologias que reforcem as relações humanas e pedagógicas em sala de aula.

É necessário lembrar que a gestão inovadora numa escola pública deve responder aos questionamentos atuais e por vezes conflitantes ao estudo de uma problemática, para buscar a solução de uma ou de várias questões oriundas do cotidiano escolar, do sistema educacional ou da formulação de uma política pública que tenha alcance geral no conjunto da educação (AMORIM, 2012). Da mesma forma, a inovação educacional, quando ocorre, é caracterizada por diferentes elementos da vida educacional, e forma um conjunto sistematizado, capaz de ser acompanhado e avaliado para verificar o alcance social, educacional e cultural das realizações efetivadas.

Por isso, afirmamos que a educação e a escola que temos hoje, no Brasil, espelha o mundo e a sociedade que ajudamos a construir até agora: uma sociedade consumista, com ideias e realizações homogêneas ou líquidas, com utopias individualistas e improváveis (BAUMAN, 2008). Mas é requisito não perder de vista que avançamos muito nos últimos anos e precisamos ter a esperança concreta de que é possível transformar a sociedade e a escola. E que a gestão escolar é apenas uma das pontes dinâmicas que precisamos construir para alterar o rumo da escola atual.

Com isso, reiteramos a relevância de: “[...] que cada escola mostre sua cara para a sociedade, que diga o que está fazendo, quais são os projetos que são efetivados, a filosofia pedagógica que segue as atribuições e responsabilidades de cada um dentro da escola" (MORAN, 2003, p. 3). É requerido que, no ambiente organizacional e inovador, a escola diga para quê está presente e firme compromissos históricos com a dinâmica de um mundo integrador, de modo a garantir qualidade e cidadania para todos que compõem a sociedade. 
Entendemos que a escola contemporânea deve contemplar princípios e valores que fortaleçam a formação e a cidadania do aluno, direcionando este processo formativo para revelar a importância de se viver em sociedade, de maneira ética, democrática e participativa. É necessário que a gestão escolar inovadora sempre veja o processo de ensino-aprendizagem como sendo unitário e estruturado de modo a valorizar e a ampliar aquilo que tem destaque na sala de aula e contribui para a efetivação da aprendizagem do aluno em inúmeras dimensões, garantindo conhecimentos, humanos e científicos, e a formação de competências e de habilidades contemporâneas, que ampliem a visão de mundo, para que o aluno possa renovar e refazer as diferentes trilhas educativas que precisa empreender em sua jornada formativa.

\section{Algumas conclusões}

Fizemos o esforço para nos reportarmos ao perfil holográfico do gestor da escola básica, considerando a tridimensionalidade holográfica face à complexidade do mundo. Nesse sentido, questionamos desafios enfrentados, referimo-nos ao contexto de dificuldades e possibilidades para termos jovens educandos alcançando a qualidade educativa sonhada e desejada pela sociedade.

Concluímos este artigo afirmando ser desejável empreender movimentos coletivos de inovação metodológica com relação ao quê e como ocorre o cotidiano organizacional, intelectual e afetivo no interior escolar, visando uma dinâmica maior: a construção de caminhos e possibilidades culturais, sociais e educacionais que promovam a própria transformação da escola em todos os aspectos, inclusive social, relacional, pedagógico e gestor.

Por isso, defendemos que é papel dos gestores, dos professores, dos alunos e da família atuarem de maneira integrada e receptiva a novas formas de possibilidades de construção de mais oportunidades, para a efetivação de um processo de aprendizagem que seja igualitário, integrador, aberto, atento às questões políticas, aos conhecimentos e informações contemporâneas. Defendemos a consolidação de uma prática curricular que inove, seja flexível, contextualizada e geradora de autonomia intelectual. Autonomia para o aluno se autoperceber como um cidadão construtor do mundo ético, e, portanto, respeitado, sendo capaz de valorizar a sua imagem e experiência interior, podendo crescer individual e coletivamente, projetando resultados de qualidade em sua aprendizagem, em sua vida pessoal e coletiva. 
Nesse movimento transformador e inovador da escola, é necessário seguir o ideário traçado por Dourado (2007), quando diz ser fundamental que o gestor procure oferecer qualidade na estrutura organizacional, tornando o trabalho pedagógico dinâmico e compatível com o interesse das comunidades interna e externa, zelando pela implantação de uma metodologia de trabalho colaborativo, como sinônimo de qualidade humana e pedagógica.

Há ainda a perspectiva inovadora de valorização do trabalho das equipes gestora e pedagógica, incentivando a efetiva participação da comunidade local na discussão e no desenvolvimento dos diferentes momentos institucionais, criando, assim, um clima dinâmico, voltado para a construção de uma cultura de qualidade capaz de promover a emancipação, a cidadania, a ética, a integração, a justiça social e acompanhar a dinâmica da vida em sociedade em todas as suas facetas holográficas.

\section{REFERÊNCIAS}

AMORIM, A. Escola - uma instituição social complexa e plural. São Paulo: Editora Viena, 2007.

AMORIM, A. et al (Orgs). Educação e contemporaneidade: processos e metamorfoses. Rio de Janeiro: Editora Quartet, 2009.

AMORIM, A. Políticas públicas em educação, tecnologia e gestão do trabalho docente. Salvador: EDUNEB, 2012.

AMORIM, A.; SANTOS, C. L. dos.; CASTAÑEDA, J. A. S. Inovação da gestão dos saberes escolares: fator de promoção da qualidade do trabalho pedagógico. Salvador: Revista da FAEEBA, Salvador, v. 21, n. 38, p. 114-126, 2012.

AMORIM, A. Inovação, qualidade do ensino e saberes educacionais: caminhos da gestão escolar contemporânea. Revista Ibero-Americana de Estudos em Educação. Araraquara, v. 10, n. 2, p. 400-416, 2015.

BAUMAN, Z. O medo líquido. Rio de Janeiro: Jorge Zahar, 2008.

BRANDÃO, Z. (Org). A crise dos paradigmas e a educação. 10 ed. São Paulo: Cortez. 2005.

BRASIL. Ministério da Educação. Censo Escolar de 2013.

BRASIL. Ministério da Educação. Censo Escolar de 2014.

BRASIL. Ministério da Educação. Censo Escolar de 2015. 
BRASIL. Censo Escolar da Educação Básica 2013 - Resumo Técnico. Ministério Da Educação. Instituto Nacional de Estudos e Pesquisas Educacionais Anísio Teixeira. Diretoria de Estatísticas Educacionais. Brasília - DF. 2014. Disponível em:

<http://download.inep.gov.br/educacao_basica/censo_escolar/resumos_tecnicos/resumo _tecnico_censo_educacao_basica_2013.pdf>. Acesso em: 24 jun. 2016.

CRESWELL, J. W. W. Projeto de pesquisa: métodos qualitativo, quantitativo e misto. 2. ed. Porto Alegre: Bookman, 2010.

DOURADO, L. F. et al. A qualidade da educação: conceitos e definições. Brasília: MEC, 2007.

FREITAS, K. S. de.; PILLA, S. B. Gestão democrática da educação. In: BRASIL. Ministério da Educação. Secretaria Educação Básica. Pradime: Programa de Apóio aos Dirigentes Municipais de Educação. Caderno de textos, $n^{\circ}$ 3. Brasília, DF, p. 13-70, 2006.

FREITAS, K. S. de.; ROCHA, A. F. Políticas de formação de dirigentes escolares par ao ensino básico no Brasil e na Argentina e Educação em Direitos Humanos. In CUNHA, C. da.; SOUSA, J. V.; SILVA, M. A. (Org.) Internacionalização da educação: discursos práticas e reflexos sobre as políticas educativas. Belo Horizonte, M.G.: Fino Traço, 2016,

FERNANDES, M. E. A. Gestão da escola: desafios a enfrentar. Rio de Janeiro: DP\& A Editora, 2002.

JOVCHELOVITCH, S. Cultura e Pesquisa. Representações sociais: Saberes sociais e polifasia cognitiva. EduCadernos, Blumenau, Caderno 2, p. 1 - 56, 2001.

LUCK, H.; FREITAS, K. S. de.; GIRLING, R.; KEITH, S. A escola participativa: o trabalho do gestor escolar. Petrópolis, RJ.: Editora Vozes, 2012.

MORAN, J. M. Gestão inovadora da escola com tecnologias. In: VIEIRA, Alexandre (org.). Gestão educacional e tecnologia. São Paulo: Avercamp, 2003.

MUÑOZ, C. C. Del mapa escolar al territorio educativo: disoñando la escuela desde la educación, Santiago: Editorial Nueva Mirada, 2007.

PARO, V. H. Gestão escolar, democracia e qualidade do ensino. São Paulo: Ática, 2007.

VEIGA, I. P. A. (org.). Projeto Político Pedagógico: uma construção possível. São Paulo: Cortez, 2001. 


\section{Como referenciar este artigo}

AMORIM, Antonio.; MATTA, Alfredo Eurico da.; FREITAS, Kátia Siqueira de FREITAS. O retrato holográfico do gestor da escola básica e a necessidade de novas possibilidades gestoras. Revista Ibero-Americana de Estudos em Educação, Araraquara, v. 12, n. 3, p. 1802-1819, jul-set/2017. Disponível em: <http://dx.doi.org/10.21723/riaee.v12.n.3.2017.8751>. E-ISSN: 1982-5587.

Submetido em: 01/07/2016

Aprovação final em: 14/05/2017 